\title{
Assessment of right ventricular regional contraction and comparison with the left ventricle in normal humans: a cine magnetic resonance study with presaturation myocardial tagging
}

Hiroaki Naito, Jun Arisawa, Koushi Harada, Hidetoshi Yamagami, Takahiro Kozuka, Shinichi Tamura

\begin{abstract}
Objective-Right ventricular regional contractility has been thought to be difficult to assess precisely. Cine magnetic resonance imaging with presaturation myocardial tagging was employed to quantitate the contraction of the right ventricular free wall and to identify normal performance compared with the left ventricle.
\end{abstract}

Methods-Nine normal volunteers, aged 27-39 years, were examined in a 1.5 Tesla superconductive magnet, and short axis and four-chamber sections at the midventricular level were imaged with cine magnetic resonance sequences. Tags, applied at end diastole as two parallel black lines, intersected the mid-portion of the free wall, dividing it into upper, centre, and lower segments in the short axis section, and anterior, middle, and posterior segments in the four-chamber section. From a series of cine magnetic resonance images at $50 \mathrm{~ms}$ intervals over a cardiac cycle, end diastolic, and early, mid-, and end systolic images were chosen for calculation of the endocardial, epicardial, and mean percent fractional shortenings (\%FS) in the six segments.

Division of Functional Diagnostic Imaging, Department of Analytical Radiology, Biomedical Research Centre, Osaka University Medical School, Osaka, Japan H Naito

$S$ Tamura

Department of Radiology, Osaka University Medical School, Osaka, Japan

J Arisawa

K Harada

H Yamagami

T Kozuka

Correspondence to:

Dr $\mathrm{H}$ Naito, Division of Functional Diagnostic Imaging, Department of Imaging, Department Analytical Radiology, Biomedical Research
Centre, Osaka University Medical School, 2-2 Yamada-oka, Suita, Osaka 565, Japan.

Accepted for publication 20 December 1994 Results-There was (1) a gradual increase in \%FS in systole in both sections $(P<0.001,<0.005)$; (2) a poor transmural gradient of contractility; (3) a predominance of meridional shortening (whole length, mean end systolic \%FS (SD): short axis, $17 \cdot 4$ (3.1)\%; fourchamber, $30.1(4.1) \% ; P<0.001)$ in contrast to dominant circumferential shortening in the left ventricular lateral wall; (4) lower predominance of contractility in the short axis section $(P<0.001)$, and a middle dip of contractility in the four-chamber section ( $P<0.005)$.

Conclusions-Heterogeneity of contractility was closely correlated with the myocardial fibre architecture, and with wall stress determined by its thickness and curvature. It was proved that right ventricular regional function could be analysed non-invasively using cine magnetic resonance imaging with myocardial tagging.
(Br Heart f 1995;74:186-191)

Keywords: Regional contraction; right ventricle; cine magnetic resonance imaging; presaturation tagging

Although the significance of an assessment of right ventricular function is well recognised, especially for patients with congenital cardiac anomalies and with valvular heart diseases, no standard approach to this has been established because of the complex configuration and non-concentric nature of the contraction of the ventricle. Some basic indices reflecting the global function of the right ventricle, such as cavity volume and ejection fraction, can be estimated by using conventional angiocardiography $^{1-3}$ or radionuclide scintigraphy, ${ }^{45}$ but the results lack accuracy and do not always reflect regional dysfunction. Right ventricular regional contractility, which may be more sensitive to maladaptation to overload, has been considered to be much more difficult to assess precisely than global function, and very few reports have appeared discussing regional contraction of the right ventricle even in experimental researches. ${ }^{67}$

At the present time, we can easily depict the right ventricle by proton magnetic resonance (MR) imaging. Recently, non-invasive myocardial marking was also achieved by using a presaturation technique, in which the capacity of proton spins to absorb the energy of electromagnetic waves is depleted by saturating the spins with irradiation just before the imaging irradiation, producing a loss of the MR signal. When this is applied, marks (or tags) appear as black lines on the myocardium. Several methods of myocardial tagging have been proposed ${ }^{89}$ and they have begun to be used for precise in vivo measurement of regional shortening of the left ventricular wall. ${ }^{10}$

The purpose of the present study was to quantitate the regional contraction of the right ventricular free wall and to identify normal performance in comparison with the left ventricle in humans by applying cine MR imaging combined with presaturation myocardial tagging. As regional contraction abnormalities are expected to lead to early detection of right ventricular dysfunction, 

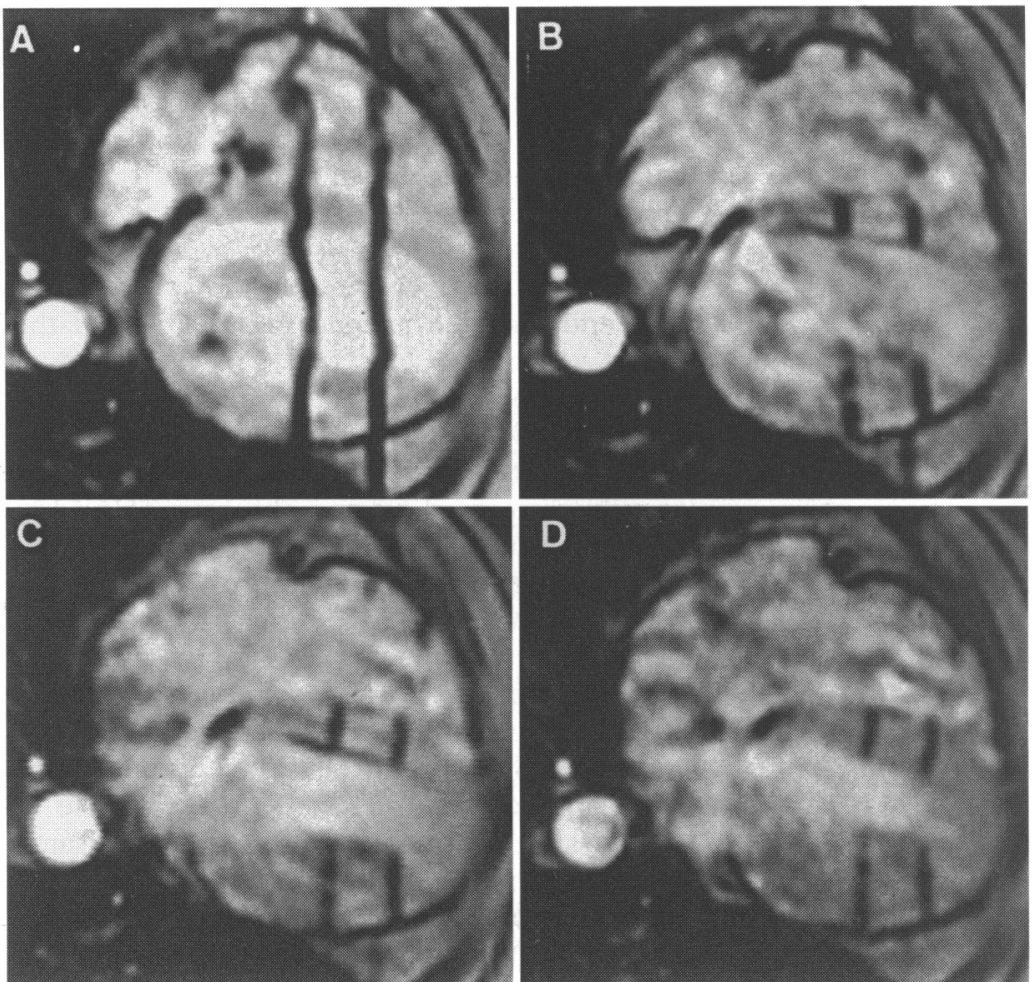

Figure 1 Four images of both ventricles in the four-chamber section looking cephalad, extracted from one cine $M R$ imaging series. Two vertical tag lines $5 \mathrm{~mm}$ in width were applied at end diastole: $(A)$ end diastole; (B) early systole; $(C)$ mid-systole; and $(D)$ end systole. Note that the motion of the right ventricular free wall is more prominent than that of the left ventricle.

information on normal contraction will have significant clinical importance when such tagging is applied to the diseased heart.

\section{Methods}

The subjects were nine healthy male volunteers, ranging in age from 27 to 39 years, mean(SD), $32 \cdot 3(4 \cdot 2)$ years. All were in nor-

Short axis

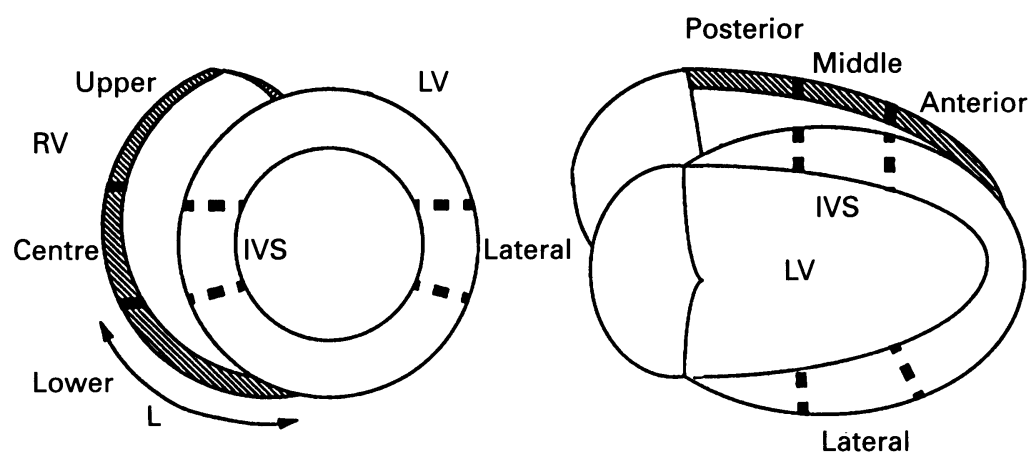

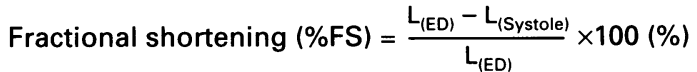

$$
\begin{aligned}
& \text { Mean fractional shortening }=\left(\% \mathrm{FS}_{\text {end }}+\% \mathrm{FS}_{\text {epi }}\right) \times 1 / 2
\end{aligned}
$$

Figure 2 Percent fractional shortenings (\%FS) of endocardial and epicardial contours and the average of both (mean $\% F S$ ) were calculated for the whole length and six segments of the right ventricular $(R V)$ free wall, as shown in this drawing. $L V$, left ventricle; IVS, interventricular septum; $L$, length of contour of the whole wall or wall segment; ED, end diastole; end, endocardium; epi, epicardium. mal sinus rhythm, and heart rate ranged from 55 to $85 / \mathrm{min}$ (mean, 66.1). None had clinical evidence of any cardiovascular abnormality, or any abnormality on electrocardiogram (ECG) or on echocardiography. All were examined on a 1.5 Tesla superconductive MR imaging system (Magnetom H15, Siemens). After the subject was positioned in the imager, brief ECG triggered spin echo multislice sequences were performed to scout for sections for cine MR imaging with presaturation myocardial tagging, and two sections (a short axis section and a four-chamber section), both intersecting at about the mid-ventricular level, were chosen for the imaging.

The cine MR imaging used here was based on the fast low angle shot (FLASH) technique using a gradient field echo sequence with a flip angle of 30 degrees, combined with velocity rephasing. Images at the same level, with an echo time of $8 \mathrm{~ms}$, were obtained sequentially from a triggered $R$ wave to the next $R$ wave with a $50 \mathrm{~ms}$ interval. The slice thickness was $10 \mathrm{~mm}$. The imaging field of view was $35 \mathrm{~cm}$ with a matrix of $192 \times 256(192$ phase encoding steps) and single data acquisition was employed, so several minutes (192 cardiac cycles) were required to produce one cine $M R$ imaging series. For presaturation tagging, irradiation of electromagnetic waves with a flip angle of $90^{\circ}$ was performed at the $R$ wave of the ECG. As completely simultaneous excitation of proton spins in two parallel planes was available in our system, we used this for presaturation in the form of a pair of planes of $5 \mathrm{~mm}$ thickness and 1.5-2.5 $\mathrm{cm}$ apart, perpendicular to the imaging plane; consequently, two narrow black lines, $5 \mathrm{~mm}$ in width, were placed on an image as tags. The presaturation procedure took several milliseconds, so the first image of a cine $M R$ series could be obtained about $15 \mathrm{~ms}$ after the $R$ wave. One series of cine MR imaging, with a pair of parallel tag lines intersecting around the mid-portion of the right ventricular free wall, was performed for the short axis section and one for the four-chamber section, and overall 18 cine series were obtained for the volunteers. Figure 1 is an example.

With the tag lines for the two cine MR imaging series, the right ventricular free wall was divided into the following six segments (fig 2): (a) short axis section: (1) upper segment (from the top of the anterior free wall to the upper tag); (2) centre segment (between the two tags); (3) lower segment (from the lower tag to the junction of the inferior free wall and the interventricular septum); (b) four-chamber section: (4) anterior segment (from the junction of the apical free wall and the interventricular septum to the anterior tag); (5) middle segment (between the two tags); (6) posterior segment (from the posterior tag to the right atrioventricular sulcus). Four images were extracted from a cine MR series according to the following criteria: (1) at end diastole, the first frame of the series; (2) at early systole, at about $10 \%$ of the $\mathrm{RR}$ interval; (3) at mid-systole, at about $20 \%$ of the RR interval; and (4) at end systole, at 
Figure 3 Reproducibility of the measurement of the mean $\% F S$ values at various cardiac phases for the six right ventricular segments. Interobserver variations between two observers $(H N, \mathcal{F} A)$ are shown. SEE, standard errors of the estimate.

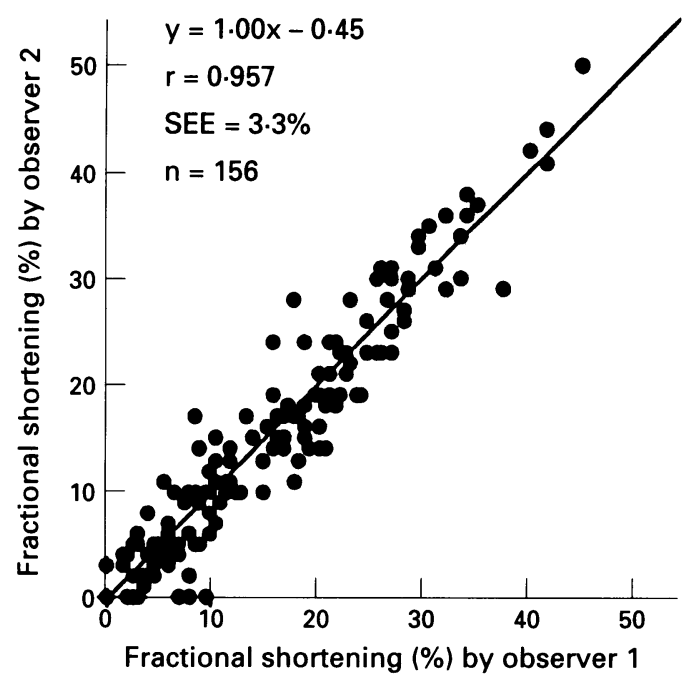

about $35-40 \%$ of the $R R$ interval and showing the minimal area of the right ventricular cavity. Among the 18 cine series, end systole was the seventh frame in 12 series and the eighth frame in six series. Each image was then manually traced, the lengths of the endocardial and epicardial contours at end

Table 1 Fractional shortening and thickness of the right ventricular free wall in the short axis section

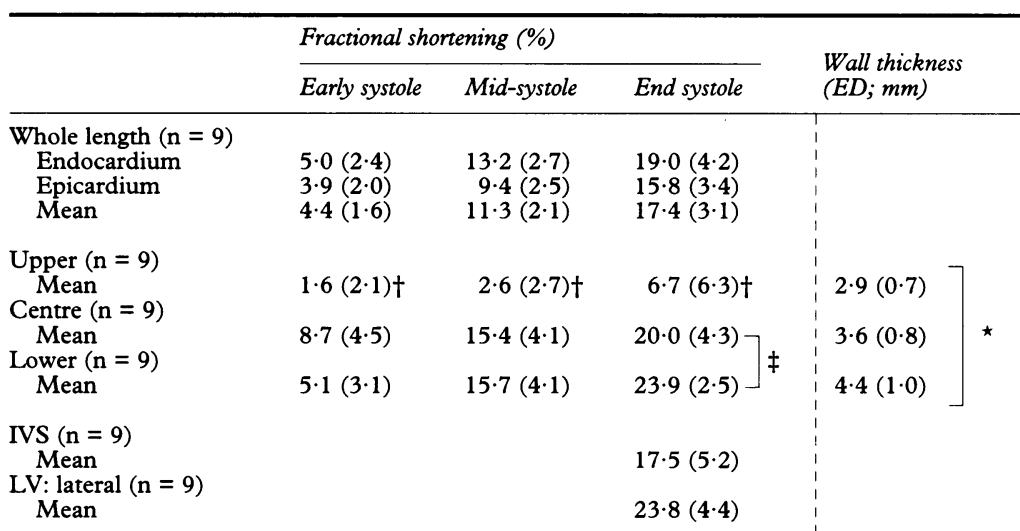

IVS, interventricular septum; LV, left ventricle. Values are mean (SD), $\mathrm{n}=$ No of materials or segments. End diastolic (ED) wall thickness at the mid-portion of each segment was reduced significantly towards the outflow ( ${ }^{\star} \mathrm{P}<0.001,<0.005,<0.05$ by paired $t$ test). The upper $\% \mathrm{FS}$ values were significantly smaller than those of the centre or lower segments throughout systole $(+\mathrm{P}<0.001,<0.005,<0.05)$. There was also a significant difference between the centre and lower \% FS values at end systole $(\ddagger P<0 \cdot 05)$.

Table 2 Fractional shortening and thickness of the right ventricular free wall in the fourchamber section

\begin{tabular}{|c|c|c|c|c|}
\hline & \multicolumn{3}{|c|}{ Fractional shortening (\%) } & \multirow{2}{*}{$\begin{array}{l}\text { Wall thickness } \\
(E D ; \mathrm{mm})\end{array}$} \\
\hline & Early systole & Mid-systole & End systole & \\
\hline $\begin{array}{l}\text { Whole length }(\mathrm{n}=9) \\
\text { Endocardium } \\
\text { Epicardium } \\
\text { Mean }\end{array}$ & $\begin{array}{l}8 \cdot 7(2 \cdot 8) \\
7 \cdot 8(2 \cdot 7) \\
8 \cdot 2(1 \cdot 8)\end{array}$ & $\begin{array}{l}22 \cdot 7(6 \cdot 1) \\
19 \cdot 6(4 \cdot 3) \\
21 \cdot 1(4 \cdot 8)\end{array}$ & $\begin{array}{l}32 \cdot 0(6 \cdot 1) \\
28 \cdot 2(2 \cdot 7) \\
30 \cdot 1(4 \cdot 1)\end{array}$ & \\
\hline $\begin{array}{l}\text { Anterior }(n=8) \\
\text { Mean } \\
\text { Middle }(n=8) \\
\text { Mean } \\
\text { Posterior }(n=9) \\
\text { Mean }\end{array}$ & $\begin{array}{r}7 \cdot 8(2 \cdot 7) \\
6 \cdot 7(4 \cdot 3) \\
10 \cdot 1(7 \cdot 0)\end{array}$ & $\begin{array}{l}23 \cdot 3(6 \cdot 1) \\
15 \cdot 1(4 \cdot 5) \dagger\end{array}$ & $\begin{array}{l}31 \cdot 3(3 \cdot 5) \\
22 \cdot 6(4 \cdot 6) \dagger\end{array}$ & $\begin{array}{l}2 \cdot 2(0 \cdot 4) \\
4 \cdot 3(1 \cdot 4) \\
5 \cdot 4(0 \cdot 7)\end{array}$ \\
\hline $\begin{array}{l}\text { IVS }(n=9) \\
\text { Mean } \\
\text { LV: lateral }(n=9) \\
\text { Mean }\end{array}$ & & & $\begin{array}{l}20 \cdot 3(4 \cdot 6) \\
15 \cdot 8(5 \cdot 9)\end{array}$ & \\
\hline
\end{tabular}

IVS, interventricular septum; LV, left ventricle. Values are mean (SD), $\mathrm{n}=$ No of materials or segments. End diastolic (ED) wall thickness at the mid-portion of each segment was reduced significantly towards the apex ( ${ }^{\star} \mathrm{P}<0.001,<0.005,<0.05$ by paired $t$ test). The middle $\% \mathrm{FS}$ values were significantly smaller than those of the anterior or posterior segments in mid- to endsystole $(† P<0.005,<0.05)$. diastole and the following three systolic phases were measured for the whole free wall and for the six segments, and the systolic percent fractional shortenings (\%FS) to end diastole were calculated in the manner shown in fig 2. The mean shortening of the wall or segment was defined as the average of the endocardial and epicardial \%FS values. For the end diastolic image, the thickness of the right ventricular free wall was measured at the mid-portion of each segment. The image tracings, \%FS calculations, and measurements of the wall thickness were independently performed by two observers (HN, JA) and their average values were accepted as the data for the following analysis.

Values of \%FS for different locations and at different cardiac phases were compared with each other. For comparison with the left ventricular contraction performance, the mean \%FS values of the interventricular septum and lateral wall of the left ventricle at end systole, obtained previously in the same manner as in the present study (see fig 2) and reported (by Naito $\mathrm{H}$ et al, abstract, Jpn Circ Soc, 1991), were included in this analysis. The regional difference of the end diastolic wall thickness was also analysed. The significance of the differences in these values was examined statistically by a paired Student's $t$ test.

\section{Results}

Interobserver variability in measuring the mean percent fractional shortening ( $\% \mathrm{FS})$, the average of the endocardial and epicardial $\% \mathrm{FS}$ values, is shown in fig 3 . This represented only a small interobserver variation, with a high correlation coefficient $(0.957)$ and small standard errors of the estimate (3.3\%).

Values of \%FS and end diastolic thickness of the right ventricular free wall are shown in table 1 (short axis section) and table 2 (fourchamber section), including the mean \%FS values of the septum and left ventricular lateral wall. As shown in the two tables, the right ventricular wall was relatively thick at the inferior or basal portion, becoming significantly thinner towards the outflow or apex ( ${ }^{\mathrm{P}}<0.001,<0.005,<0.05$ in both tables).

Figure 4 is a graphic representation of the time dependence of the $\% \mathrm{FS}$ for whole length of the free wall. Both the endocardial and epicardial side of the wall shortened significantly from end diastole to end systole $(P<0.001$, $<0.005)$ in the short axis and the four-chamber section. In each of the three systolic phases, the endocardial \%FS was slightly higher than that for the epicardium; the only significant differences found were at midsystole in the short axis section $(P<0.01)$ and end systole in the four-chamber section $(P<0.05)$. On the other hand, the \%FS of the four-chamber section was significantly high compared with that of the short axis section, for both the endocardium and the epicardium throughout systole $(\mathbb{P}<0.001$ to $<0.05)$. The mean values $(S D)$ of the mean 


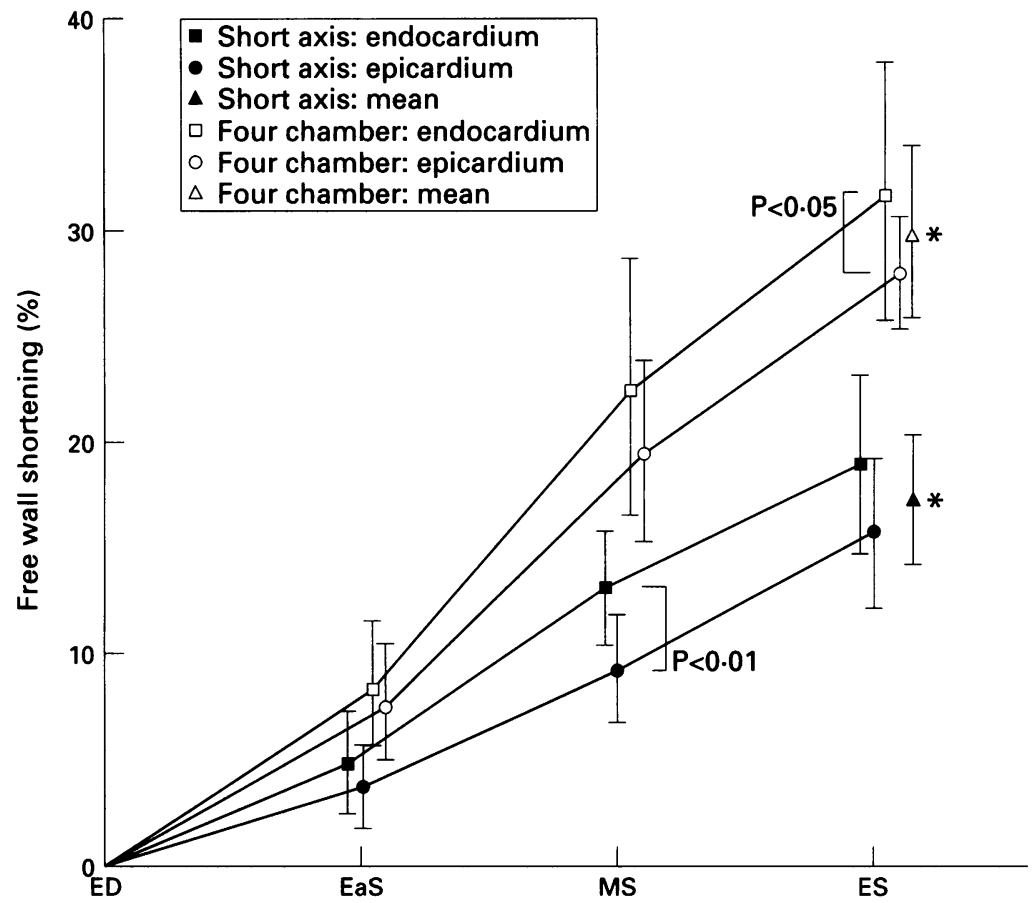

Figure 4 Time dependence in the cardiac cycle and endocardial-epicardial difference in $\% F S$ of the right ventricular free wall (whole length) in the short axis and four-chamber sections. Mean values with standard deviations are shown. End systolic \%FS in the short axis section was significantly smaller than that in the four-chamber section (*endocardium: $P<0.005$, epicardium: $P<0.001$, mean: $P<0.001$ by a paired $\mathrm{t}$ test). ED, end diastole; EaS, early systole; $M S$, mid-systole; $E S$, end systole.

$\% \mathrm{FS}$ at end systole were $17 \cdot 4(3 \cdot 1) \%$ for the short axis section and $30 \cdot 1(4 \cdot 1) \%$ for the four-chamber section, the latter being significantly higher (fig $4, \mathrm{P}<0.001$ ).

As for regional differences, the $\% \mathrm{FS}$ of the upper segment was significantly small compared to that of the centre or lower segment, not only at early systole $(P<0.005,<0.05)$ but also at mid- to end systole $(P<0.001)$ in the short axis section ( $\dagger$ in table 1$)$. The

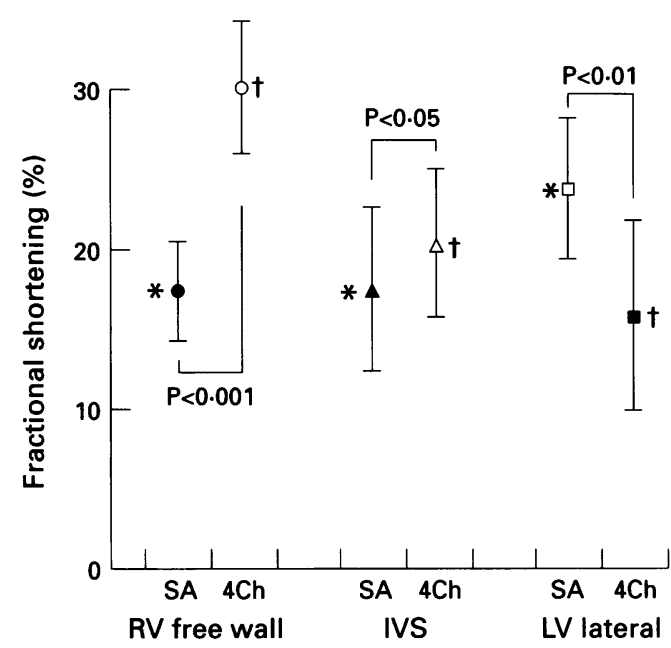

Figure 5 Differences of the mean \%FS at end systole among the right ventricular (RV) free wall (whole length), the interventricular septum (IVS), and the lateral wall of the left ventricle (LV). Mean values with standard deviations are shown. The \%FS of the $L V$ lateral wall was significantly higher than in the $R V$ wall $\left({ }^{\star} P<0.01\right)$ and the IVS $\left({ }^{*} P<0.05\right)$ in the short axis section. On the other hand the \%FS values of the four-chamber section showed a significant decrease from the $R V$ to the IVS $(+P<0.001)$ and from the IVS to the LV lateral wall $(+P<0.01)$. SA, short axis; $4 \mathrm{Ch}$, four-chamber. centre $\% \mathrm{FS}$ was also small compared to that of the lower segment at end systole, with weak significance $(P<0.05)$. There was little shortening of the middle segment compared to the other two segments at mid-systole $(P<$ $0.05)$ and end systole $(P<0.005)$ in the fourchamber section ( + in table 2 ). Consequently, at end systole, a significant gradient of contractility could be found from the lower to the upper segment in the short axis section; and there was a significant middle dip of contractility in the four-chamber section.

When compared with the left ventricle, in the right ventricular free wall meridional contraction was more dominant than the circumferential contraction $(P<0.001)$, whereas the dominance was reversed in the left ventricular lateral free wall $(P<0.01)$ (fig 5 ). In the short axis section, the $\% \mathrm{FS}$ of the left lateral wall was higher than the \%FS values of the right ventricular and septal walls $(P<0.01$, $<0.05$ ), whereas in the four-chamber section, a significant gradient of $\% \mathrm{FS}$ was confirmed from the right ventricular wall to the left lateral wall through the interventricular septum $(\mathrm{P}<0.001,<0.01)$.

\section{Discussion}

In contrast to the left ventricle, few experimental studies have been conducted on right ventricular regional contraction. ${ }^{67}$ This may be because the usual approach to studying the left ventricle-open chest implantation of ultrasonic myocardial markers followed by echocardiographic observation ${ }^{11-13}$-is hardly applicable to the right ventricle. Anzola ${ }^{6}$ measured regional shortening of the right ventricular wall with a variable resistance gauge sutured on to the epicardial surface of the dog heart, and reported that epicardial percent fractional shortening (\%FS) was around $15 \%$. Raines et al reported the epicardial $\% \mathrm{FS}$ (SE) of the canine right ventricular inflow tract as $13(1 \cdot 3) \%$ according to echocardiographic assessment of the motion of implanted crystals. As for short axial circumferential shortening, our results for the epicardial \%FS $(17 \cdot 4 \%)$ do not differ greatly from these reported values. We have previously measured epicardial shortening by ECG gated computerised tomography in patients with ischaemic heart disease, ${ }^{14}$ and obtained a normal $\%$ FS value(SD) of $27 \cdot 8(5 \cdot 0) \%$ in a mid-ventricular four-chamber section, almost the same as that in this study $(28 \cdot 2 \%)$. The clinically estimated normal value of the right ventricular ejection fraction has been reported to be about $60 \%$ in conventional right ventriculography ${ }^{1-3}$ and $50-55 \%$ in radionuclide scintigraphy, ${ }^{45}$ which are roughly comparable with the average of the short axis and fourchamber endocardial $\% \mathrm{FS}$ values of the whole free wall at end systole in this study $(25.5 \%)$, and the ejection fraction estimated from the value $(59 \%)$.

We could confirm the existence of meridional predominance of contraction in the normal right ventricular free wall, which was suggested from the data in Anzola's report. ${ }^{6}$ 
Significant regional heterogeneity of contractility was also observed in the free wall, that is, apical and posterior predominance resulting in a middle dip in the four-chamber section and lower predominance in the short axis section. A previously reported temporal asyn$\mathrm{ergy}^{7}$ - an initial delay in the outflow contraction from that in the inflow tract correlating to the timing of electrical excitation ${ }^{15}$ (which was suggested in this study as a significantly small \%FS at early systole in the upper segment)-was not determined because there was only minor shortening of the segment throughout systole. Compared with the left ventricle, a prominent difference was found in the dominant direction of contraction at both ventricular free walls. Both a transmural gradient and apical predominance of contractility have been demonstrated in left ventricular regional heterogeneity, ${ }^{11-1316}$ but the former was found with weak or of no significance in the right ventricle, perhaps due to the wall being thinner than that of the left ventricle.

The heterogeneity of ventricular contraction obtained here in normal subjects could be associated with two biological factors: the myocardial fibre architecture, and wall stress determined by the thickness and curvature of the wall and blood pressure. ${ }^{1718}$ Figure 6 is a schematic drawing of the myocardial fibre architecture of both ventricles reconstructed from published data. ${ }^{19-23}$ Although the basic structure of the sinus portion of the two ventricles has been stated to be the same, ${ }^{2021}$ this figure shows that while longitudinal or oblique fibres are predominant in the right ventricular free wall, circular mid-wall fibres predominate in the left ventricular lateral

Myocardial fibre architecture

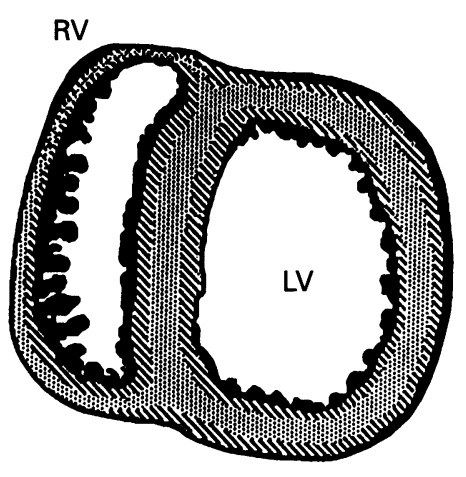

Short axis

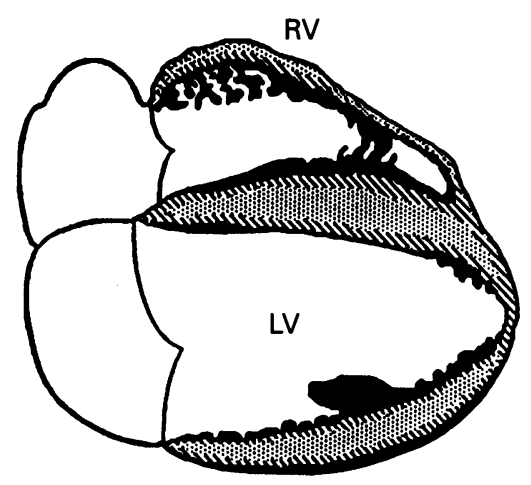

Four chamber
Longitudinal

Figure 6 Schematic drawing of the myocardial fibre architecture of both ventricles. Figure 6 Schematic drawing of the myocardial fibre architecture of both ventricles.
According to the fibre angle from the circumferential direction, the three layers depicted are roughly defined as follows: circular layer, around $0^{\circ}\left( \pm 20^{\circ}\right)$; oblique layer, $\pm 20^{\circ}$ to $45^{\circ}$; longitudinal layer, over $\pm 45^{\circ}$. The longitudinal layer is relatively predominant in the right ventricular $(R V)$ free wall, whereas the circular layer predominates in the left ventricular (LV) lateral wall; the interventricular septum has medium amounts of both. wall, and there are medium amounts of both in the interventricular septum. This agrees well with the dominance of meridional contraction in the right ventricular wall and of circumferential contraction in the left ventricular lateral wall. As regards the regional heterogeneity of right ventricular contractility, wall stress would be the main cause, because it is closely correlated with heterogeneity of the thickness and curvature, that is, the lower or posterior segment has a relatively thick wall with a large curvature, whereas the upper to centre, or middle segment, is rather flat. The dominant contractility at the anterior segment, in spite of its thinness, was thought to be mainly due to the large curvature, and possibly to assistance in contraction from the moderator bands. Apart from these two factors, adrenergic function may have some influence on the heterogeneity, as the concentration of noradrenaline was reported to be higher in the cardiac base than in the apex, with a gradient of distribution. ${ }^{24} 25$

The method used here had several technical limitations, such as the quality of the temporal resolution of cine $M R$ imaging, and difficulties in determining the endocardial boundary and in compensating for the through plane motion of the heart. Although an imaging interval of $50 \mathrm{~ms}$ is insufficient for precise determination of the phase in the cardiac cycle, the cine MR sequence appears to be acceptable enough to analyse late systolic contractility. Cine MR imaging also has the drawback that, because the endocardial boundary is often obscure due to the high intensity depiction of the ventricular cavity, errors can occur in measuring the endocardial length or thickness of the wall. The transmural gradient of contractility, however, was found to be small in the normal right ventricle, so its influence on the \%FS values obtained in this study would have been negligible. The applied tag lines, which persisted on the myocardium and flowed away from the cavity in systole, were extremely helpful for measurements of wall thickness. The through plane motion of the heart is the major problem in assessing right ventricular regional contraction; we coped with it by choosing the mid-ventricular section for the imaging. As a prominent meridional excursion of the right ventricular free wall was found in this study, and is commonly observed in conventional right ventriculography, the short axial systolic shortening, especially in the upper segment, might be somewhat underestimated because of the systolic entrance of the more basal portion of the ventricle into the imaging plane. The myocardial tag, applied as a thin plane perpendicular to the imaging plane, does not disappear from the image during the through plane motion.

In spite of the limitations cited, there is no doubt that only the presaturation tagging technique of $\mathrm{MR}$ imaging can provide noninvasive myocardial marking at the present time. In this study, the technique was also proved to be capable of measuring right ventricular regional contraction. MR myocardial 
tagging is therefore expected to become an extremely useful new tool not only for the early detection of right ventricular dysfunction in patients with ventricular overload, but also for the assessment of ischaemic abnormalities of the right ventricular wall, and for the planning for right ventricular reconstructive surgery. We believe that the information presented here will be of fundamental importance for these evaluations.

1 Gantzler RD, Briselli MF, Gault JH. Angiographic estimation of right ventricular volume in man. Circulation 1974;50:324-30.

2 Ferlinz J, Gorlin R, Cohn PF, Herman MV. Right ventricular performance in patients with coronary artery ular performance in patients with

3 Redington AN, Gray HH, Hodson ME, Rigby ML, Oldershaw PL. Characterisation of the normal right ventricular pressure-volume relation by biplane angiography and simultaneous micromanometer pressure measurements. Br Heart $\mathcal{f}$ 1988;59:23-30.

4 Berger HJ, Matthay RA, Loke J, Marshall RC, Gottschalk A, Zaret BL. Assessment of cardiac performance with quantitative radionuclide angiocardiography: right ventricular ejection fraction with reference to findings in chronic obstructive pulmonary disease. Am $₹$ Cardiol 1978;41:897-905.

5 Maddahi J, Berman DS, Matsuoka DT, Waxman AD, Stankus KE, Forrester JS, et al. A new technique for Stankus KE, Forrester JS, et al. A new technique for
assessing right ventricular ejection fraction using rapid assessing right ventricular ejection fraction using rapid
multiple gated equilibrium cardiac blood pool scintimultiple gated equilibrium cardiac blood pool scinti-
graphy: description, validation and findings in chronic coronary artery disease. Circulation 1979;60:581-9.

6 Anzola J. Right ventricular contraction. Am $f$ Physiol 1956;184:567-71

7 Raines RA, LeWinter MM, Covell JW. Regional shortening patterns in the canine right ventricle. Am $\mathcal{F}$ Physiol 1976;231:1395-400.

8 Zerhouni EA, Parish DM, Rogers WJ, Yang A, Shapiro EP. Human heart: tagging with MR imaging - a method for noninvasive assessment of myocardial motion. for noninvasive assessme
Radiology 1988;169:59-63.

9 Axel L, Dougherty L. Heart wall motion: improved method of spatial modulation of magnetization for MR imaging. Radiology 1989;172:349-50.

10 Clark NR, Reichek N, Bergey P, Hoffman EA, Brownson $\mathrm{D}$, Palmon L, et al. Circumferential myocardial shorten- ing in the normal human left ventricle: assessment by magnetic resonance imaging using spatial modulation of magnetization. Circulation 1991;84:67-74.

11 Gallagher KP, Osakada G, Matsuzaki M, Miller M, Kemper WS, Ross J. Nonuniformity of inner and outer systolic wall thickening in conscious dogs. Am $\mathcal{f}$ Physiol 1985;249:H241-8.

12 Homans DC, Sublett E, Lindstrom P, Nesbitt T, Bache RJ. Subendocardial and subepicardial wall thickening during ischemia in exercising dogs. Circulation 1988; during isch $1267-76$

13 LeWinter MM, Kent RS, Kroener JM, Carew TE, Covell $\mathrm{JE}$. Regional differences in myocardial performance in the left ventricle of the dog. Circ Res 1975;37:191-9.

14 Naito H, Kimura $M$, Ohta $M$, Kimura $K$, Takamiya $M$, Kozuka $T$. Evaluation of right ventricular wall contractility in ischemic heart disease by cardiac computed tomography (in Japanese, with English abstract). $\mathcal{F}$ Cardiogr 1984;14:15-28.

15 Durrer D, Van Dam RT, Freud GE, Janse MJ, Meijler FL, Arzbaecher RC. Total excitation of the isolated human heart. Circulation 1970;41:899-912.

16 Shapiro E, Marier DL, St John Sutton MG, Gibson DG. Regional non-uniformity of wall dynamics in normal left ventricle. $B r$ Heart f 1981;45:264-70.

17 Fifer MA, Grossman W. Measurement of ventricular volumes, ejection fraction, mass, and wall stress. In: Grossman W, ed. Cardiac catheterization and angiocardiography, 3rd ed. Philadelphia: Lea and Febiger, 1986:
282-300.

18 Mirsky I. Elastic properties of the myocardium: a quantitative approach with physiological and clinical applications. In: Berne RM, ed. Handbook of physiology: the cardiovascular system, sect 2 , vol 1. Bethesda: American cardiovascular system, sect 2, vol 1. Beth
Physiological Society, 1979:497-531.

19 Williams PL, Warwick R, Dyson M, Bannister LH. Williams PL, Warwick R, Dyson M, Bannister LH.
Myocardial architecture. In: Gray's anatomy, 37th ed. Edinburgh: Churchill Livingstone, 1989:717-8.

20 Mall FP. On the muscular architecture of the ventricles of the human heart. Am $\mathcal{f}$ Anat 1911;2:211-66.

21 Armour JA, Randall WC. Structural basis for cardiac function. Am ₹ Physiol 1970;218:1517-23.

22 Greenbaum RA, Ho SY, Gibson DG, Becker AE Anderson RH. Left ventricular fibre architecture in man. Br Heart f 1981;45:248-63.

23 Streeter DD, Spotnitz HM, Patel DP, Ross J, Sonnenblick EH. Fiber orientation in the canine left ventricle during EH. Fiber orientation in the canine left ventric
diastole and systole. Circ Res 1969;24:339-47.

24 Angelakas ET. Regional distribution of catecholamines in the dog heart. Circ Res 1965;16:39-44.

25 Pierpont GL, DeMaster EG, Cohn JN. Regional differences in adrenergic function within the left ventricle. Am F Physiol 1984;246:H824-9. 